\title{
SUBJETIVIDADE E DIFERENÇA: IMPLICAÇÕES PARA OS ESTUDOS INTERCULTURAIS EM EDUCAÇÃO
}

\author{
SUBJECTIVITY AND DIFFERENCE: IMPLICATIONS FOR THE INTERCULTURAL STUDIES IN EDUCATION
}

SUBJETIVIDAD Y DIFERENCIA: IMPLICACIONES EN LOS ESTUDIOS INTERCULTURALES EN EDUCACIÓN

\author{
BONA, Juiano ${ }^{1}$ \\ BONA, Camila Thaisa Alves² \\ LUNA, José Marcelo Freitas de ${ }^{3}$
}

\section{RESUMO}

Em nosso momento histórico, parece ser consenso o fato de que vivemos em um mundo de diversidades culturais, sendo os seus aspectos geográficos objetos de pesquisa na área dos Estudos Culturais desde, pelo menos, o início do século XX. Para além desse foco, os estudos interculturais em educação, particularmente, analisam as relações que podem ser construídas entre as diferentes culturas. Os estudos de Candau (2002) permitem-nos afirmar que a construção dessas relações exige uma percepção particular do conceito de diferença em diferentes níveis. Em torno desta problemática, o objetivo geral deste artigo é analisar a relação entre o conceito de diferença e os estudos interculturais em educação.

Palavras-chave: Estudos interculturais em educação. Conceito de diferença. Sujeito intercultural.

\section{ABSTRACT}

In our historical moment, seems to be consensus the fact that we live in a world of cultural diversities. More than pointing out cultural diversities and their geographical aspects, intercultural studies in education analyze the relationships that can be built between different cultures. Candau's (2002) studies allows us to assume that building these relationships requires a particular perception of the concept of difference at different levels. Thus, the general objective of this article is to analyze the relationship between the concept of difference and intercultural studies in education.

Keywords: Intercultural studies in education. Concept of difference. Intercultural subject.

\section{RESUMEN}

En nuestro momento histórico parece ser consenso mundial el hecho de que vivimos en un mundo de diversidades culturales. Más que señalar las diversidades culturales y sus aspectos geográficos, los estudios interculturales en educación analizan las relaciones que pueden ser construidas entre las diferentes culturas. Sin embargo, construir estas relaciones exige una percepción particular del concepto de diferencia en diferentes niveles. De esta forma, el objetivo general de este artículo es analizar la relación entre el concepto de diferencia y los estudios interculturales en educación.

Palabras clave: Estudios interculturales en educación. Concepto de diferencia. Sujeto intercultural.

\footnotetext{
1 Universidade do Vale do Itajaí - UNIVALI - Itajaí - Santa Catarina - Brasil

2 Rede Municipal de Timbó - Timbé - Santa Catarina - Brasil

3 Universidade do Vale do Itajaí - UNIVALI - Itajaí - Santa Catarina - Brasil
} 


\section{INTRODUÇÃO}

Nas últimas décadas, muitos estudos foram desenvolvidos tomando como foco as relações interculturais (CANDAU 2002). Os estudos aos quais nos referimos parecem se articular com a necessidade de tornar a educação um local em que as diversidades culturais e suas relações sejam legitimadas epistemologicamente, com inserção no meio educacional via currículo. Legitimar a diversidade cultural no meio educacional implica, a princípio, a percepção e a problematização da não homogeneização, combatida por meio do tratamento horizontal, para que, posteriormente, as relações epistemológicas possam ser construídas. Isso implica uma postura epistemológica na direção da percepção das ausências, nos termos de Santos (2002), no sentido da criação conceitual da qual emerjam presenças.

Ao construir relações entre diferentes culturas, em uma espécie de trabalho de tradução (SANTOS, 2002), deparamos com uma série de problemas. O primeiro está relacionado ao tradutor, que é um sujeito forjado em seu território, em um movimento discursivo que o transforma em sujeito cultural. Trata-se, em outras palavras, da internalização do território. Podemos acoplar a este aspecto mais uma variável de forma sintética. A tradição filosófica pós-iluminismo é caracterizada pela valorização da repetição. Principalmente depois de Kant e Descartes, fomos forjados na busca da legitimação no real cultural pela ótica da repetição. Nesta lógica, a ciência só existe na repetição - o conhecimento se torna legítimo e verdadeiro se puder ser adequado às normas matemáticas. Nessa esteira, o artesão vira a madeira talhada; não existe separação entre a escultura e o artesão. Como consequência, o tradutor passa a internalizar um território transcendente, onde a razão é a rainha e a matemática, a princesa que governam o mundo da tradução. Diante desse cenário, algumas perguntas podem ser formuladas: como perceber a diversidade cultural se fazemos parte de uma tradição que privilegia a repetição como pressuposto epistemológico? Por outro lado, como podemos perceber a diversidade cultural e notar as ausências nessa diversidade, sem um sistema de referência construído a priori?

Se a percepção legitimar apenas a repetição e o padrão racional, caímos em uma lógica de colonização cultural, em que a diversidade cultural será encaixotada em princípios definidos a priori. Nesse sentido, as ausências notadas serão ilusórias, como se fossem vapores das presenças. Por outro lado, a tradução cultural exige uma gênese, que, se não for bem definida, pode cair em um espaço de caos absoluto. Desta forma, caímos em um empasse: rigidez transcendental ou caos em uma rede de discursos sem sentido. Assim, o desafio que enfrentamos é este: construir um sistema de referência epistemológico que não parta de um absoluto caos, e ao mesmo tempo, não seja um sistema de referência a priori que define o diferente tomando como referência a racionalidade cartesiana, que traduz de forma sintética a cultura eurocêntrica que se espalhou por grande parte do ocidente. Não se trata de construir um sistema de referência que tome como base o terceiro excluído de Aristóteles, pois dessa forma não conseguiríamos escapar do caos ou da racionalidade transcendental. O caminho para construção das relações interculturais, e esta é nossa tese, depende da sutileza do observador no campo das diferenças. 
É neste ponto que acreditamos estar a contribuição deste ensaio - construir conceitos que utilizem a diferença como crivo epistemológico que permite refletir sobre o pano de fundo que envolve a percepção das diferentes culturas. É essa percepção que os estudos interculturais em educação tomam como pressuposto no tratamento das relações interculturais de forma horizontal. Desta forma, o objetivo geral desse artigo é analisar a relação entre o conceito de diferença e os estudos interculturais em educação. Para isso, descreveremos o conceito de diferença (vetor $A$ ) e suas implicações nos estudos interculturais em educação (Vetor B). Como referencial teórico, utilizamos os seguintes autores: Arendt (2008), Bauman (2010), Betancourt (2004), Candau (2002), Deleuze (2000, 2017), Deleuze e Guattari (2010), Fleuri (2003), Santos (2002). Trata-se de um texto ensaístico de cunho teórico.

O texto está dividido em três partes. Na primeira parte, descrevemos o conceito de diferença. Em um segundo momento, analisamos a relação entre o conceito de diferença e os estudos interculturais em educação. Nas considerações, destacamos a possibilidade de construir um local epistemológico que permita observar a relação entre subjetividade e diferença e os estudos interculturais em educação.

\section{O CONCEITO DE DIFERENÇA - VETOR A}

A análise da soma de dois vetores na física dos corpos implica na análise dos vetores força que provocam o deslocamento do objeto. Estes componentes vetoriais podem ser observados separadamente para que posteriormente o vetor resultante possa ser analisado matematicamente. Vamos analisar nosso primeiro componente vetorial, o Vetor A - para nós, o conceito de diferença.

Representar um pensamento que expresse a diferença, ou seja, "Tirar a diferença de seu estado de maldição parece ser a tarefa da filosofia da diferença" (Deleuze, 2000, p. 38). Dentro de nossa tradição filosófica, a diferença foi amaldiçoada. A filosofia da diferença, nesse sentido, busca reconciliar a diferença com o conceito.

Construir um conceito de diferença parece a princípio negar um pressuposto importante da diferença - a não representatividade. A não representatividade se objetiva na natureza de diferentes formas. Uma folha de árvore nunca é igual a outra, mesmo que tenhamos construído um modelo de folha ideal que represente todas as folhas. Ao observar a natureza, tudo está em devir, em um fluxo contínuo de modificações.

A diferença, nesse sentido, não pode ser representada. Deleuze (2000) afirma que as vertentes filosóficas que ganharam forma na modernidade amaldiçoaram a diferença, colocando-a em uma caverna, ou seja, definindo a diferença como descolada do Ser - a diferença como não-Ser. O lluminismo de forma geral e, com mais precisão metodológica, o cartesianismo afastaram o problema da diferença, definindo a mesma como semelhança (Deleuze, 2000). A consequência imediata dessa afirmação é a referência inicial, que servirá de parâmetros de classificação. As semelhanças estão em função do sistema original, no sentido matemático do termo.

A diferença passa a não existir por ela mesma - ela só existe na semelhança, diante de um sistema de referência definido a priori. E é neste ponto que Deleuze (2000) afirma que o primeiro passo 
para reconciliar a diferença com o conceito é analisar a diferença por ela mesma. Analisá-la na imanência, sem recorrer a qualquer sistema transcendental que aprisione a diferença em um processo de classificação por grau de semelhança.

Porém, para construir o conceito de diferença, precisamos ultrapassar o modelo de sujeito cognitivo que nos interpela violenta e silenciosamente, munido de um poder discursivo que ultrapassa a fronteira sujeito e sociedade. Segundo Bauman (2010, p. 13), "o sujeito cognitivo cartesiano se expandiu para o modelo em tamanho natural do 'homem total'”. Ou seja, trata-se de um modelo de homem que percebe o real guiado pelos princípios do cogito em busca da verdade e das essências. A diferença está subordinada à semelhança de forma rígida e sistemática.

Com efeito, existe uma modelagem subjetiva que se projeta na observação. Deleuze (2000, p.131) define este modelo como sendo uma "recognição". "A recognição se define pelo exercício concordante de todas as faculdades sobre um objeto suposto como sendo o mesmo: é o mesmo objeto que pode ser visto, tocado, lembrado, imaginado e concebido" (Deleuze, p.131). Todas as faculdades passam a ser consideradas como subconjuntos do cogito cartesiano. Há, neste sentido, a construção de um sujeito que projeta um pensamento reto, constrói uma identidade do "Eu penso", que entra em acordo com o objeto que passa a ser considerado como o mesmo. Uma cultura, a dominante, será sempre a mesma: aquela que é vista, sentida, lembrada, imaginada e concebida. É por consequência, todas as outras culturas que nos afetam durante nossas experiências diárias passam despercebidas ou são negadas. A recognição passa a reforçar a igualdade entre semelhança e diferença.

Estamos diante de um processo que constrói ausências, nos termos de Santos (2002). Tudo que não se encaixa no modelo transcendental de recognição é considerado como não existente. A diferença é exorcizada do mundo das aparências através de um processo que se orienta por um modelo que enverniza a subjetividade. O Eu cartesiano isola o sujeito, definindo suas faculdades pela via da razão - a única faculdade que pode entrar em contato com os objetos. Como consequência imediata desse processo, temos a construção de uma equação considerada universal: o pensamento é igual à razão. Unificando as faculdades, o próximo passo parece ser automático: a relação entre existir e pensar se articula pela razão. O cerco está fechado e a condição "penso logo existo", neste contexto, faz sentido.

Temos a construção de um sujeito considerado universal. Deleuze (2000) afirma que a recognição é um modelo fundado na concordância das faculdades, o sujeito passa a ser considerado como um pensante tido como universal. Desta forma, a imagem do pensamento afirma um conjunto de aparências legitimadas como real, elevando-as a um nível racional. "A forma da recognição nunca santificou outra coisa que não o reconhecível e o reconhecido, a forma nunca inspirou outra coisa que não fossem conformidades" (Deleuze, 2000, p.133).

Neste sentido, para construirmos um conceito de diferença, precisamos analisar a relação entre percepção e pensamento. Acreditamos que o primeiro passo seja construir uma espécie de relação diferencial das faculdades, pois, segundo Arendt (2008, p.21), Descartes afirmava que "havia um acordo fundamental entre as leis da natureza (que estão ocultas pelas aparências e por percepções sensoriais enganosas) e as leis matemáticas". Nesta esteira, parece ser coerente, no intuito de se 
construir um conceito de diferença, retomar a lógica dos sentidos e legitimar sua produção epistemológica e subjetiva.

Primeiramente, podemos afirmar que o pensamento é maior que a razão. Isto pode ser explicado de forma simples. Existem coisas que não convidam o pensamento a um exame, pois a percepção basta para determiná-las. Por outro lado, há outras que obrigam a um exame, pois a percepção nada nos fornece de sábio. Desta forma, podemos definir que existem duas espécies de coisas: as que deixam o pensamento tranquilo e aquelas que provocam o pensamento. O primeiro está relacionado ao processo de recognição - o pensamento é aí preenchido apenas pela imagem de si mesmo, com a retomada por meio da reafirmação confortável das presenças ou a negação de que haja algum tipo de percepção que não exista. Em termos de recognição, a negação não se dá por meio da disputa - uma vez que não existe possibilidade de existência, não existe também a necessidade de tradução. É uma violência silenciosa instituída pela não consideração, pela não provocação do pensamento. $O$ Segundo, surge na provocação da dificuldade de se reconhecer alguma coisa, na violência que importuna a percepção na imagem do pensamento e em suas categorias a priori. A percepção da diferença se choca com as categorias e instiga uma reação intraduzível nos termos da razão. Assim, as condições de uma "verdadeira crítica e uma verdadeira criação são as mesmas: destruição da imagem de um pensamento que pressupõe a si próprio e a gênese do ato de pensar no próprio pensamento" (Deleuze 2000, p. 137).

Ao transformarmos a equação, pensamento igual à razão, em uma inequação, pensamento diferente de razão, as ausências são desveladas a conta gotas. As contingências forçam o pensamento e a criação se dá no próprio ato de pensar. Há coisas no mundo que forçam o pensamento. Este algo é o objeto de um encontro e não por outras faculdades. A recognição nunca é o que só pode ser sentido, a procura sempre está em função de uma estrutura que está além do que se apresenta.

É neste ponto que surge o problema da linguagem. A percepção via sentidos se relaciona com linguagens diferentes, influenciadas por relações de poder. Nesse sentido, é na linguagem que os sentidos se estruturam em uma dinâmica discursiva. Segundo Deleuze (2000), o sentido não se reduz ao objeto que se apresenta nem ao estado vivido por aquele que entra em contato com o objeto. Assim, podemos diferenciar a significação e o sentido da seguinte maneira: a significação remete apenas aos conceitos e à maneira como eles se relacionam em um campo de representação; o sentido é como as ideias que se desenvolvem nas camadas sub-representativas. Deste ponto de vista, o sentido é aquilo que não pode ser dito no uso empírico e só pode ser analisado no uso transcendente.

Não se trata, nesse sentido, de resgatar o empirismo clássico na tentativa de combater a recognição, para revelar através dos sentidos a diferença. Também, não temos a pretensão de fazer a junção entre empirismo e racionalismo, como fez Kant, pois o que percorre todas as faculdades é uma ideia que não se reduz ao sentido. É composta por elementos estruturais que não tem sentido por si só, estão no mundo do não-sentido (Deleuze, 2000). Deste ponto analítico, podemos afirmar que a diferença se revela através de uma lógica dos sentidos que se apresentam na imanência, ou seja, sem nenhum sistema metafísico. O que temos é a objetivação de um processo que amplia a transcendência na imanência. Imanência que permite analisar a diferença por ela mesma e construir um conceito de diferença. 
$\mathrm{Na}$ tentativa de cercear o que compõe o conceito de diferença, podemos afirmar: que a diferença para se revelar precisa ser analisada por ela mesma sem um sistema de referência a priori, que a recognição unifica as faculdades e constrói um tipo de pensamento reto que legitima a repetição; e que a diferença pode ser revelada a partir de uma lógica dos sentidos que se projeta nas camadas subrepresentativas da linguagem. Nesse sentido, Deleuze (2010, p.21) afirma que "todo conceito tem componentes, e se define por eles". Além disso, o conceito de diferença parece carregar em sua cifra elementos que ultrapassam qualquer tentativa de delimitação conceitual.

Desta forma, não existem conceitos simples. O conceito de diferença revela um mundo não estático, composto por elementos diferenciais. A filosofia da diferença, ou na matemática o cálculo diferencial e integral, revela um espaço de análise que o pensamento dogmático sublimou. É no campo das relações diferenciais que se apresentam na natureza, ou no campo das linguagens, que a diferença pode furar o discurso massivo, estático, que freia a velocidade do devir.

Neste ponto, parece que retornamos ao problema do pensamento e sua expressão na diferença. "No que diz respeito ao pensamento, este, mais do que conhecer alguma coisa, consiste em conhecer nossa potência de conhecer" (Deleuze 2017, p. 151). Deste ponto de vista, o conceito de diferença se revela em um processo de construção que evidencia nossa própria potência de conhecer, a gênese do pensamento no pensamento. Há, portanto, alguma coisa no pensamento que revela um conteúdo expressivo e não representativo que se projeta apenas na potência de pensar (Deleuze, 2017).

Diante desses componentes que pertencem ao conceito de diferença, falta-nos construir a relação com os estudos interculturais em educação.

\section{RELAÇÃO E CONSTRUÇÃO CONCEITUAL NOS ESTUDOS INTERCULTURAIS EM EDUCAÇÃO - VETOR B}

Um vetor se caracteriza por seu tamanho, sentido e direção. Estas características permitem não apenas prever o deslocamento do objeto, mas também analisar matematicamente o vetor resultante. Desta forma, vamos ao Vetor B.

Quando usamos a palavra relação, não estamos nos referindo a um tipo de ligação dicotômica pautada em uma lógica funcional de estímulo-resposta. Pensamos a relação em um ambiente rizomático ou fractal. Usar a palavra relação nesse contexto pressupõe duas considerações: a primeira é que, em um contexto rizomático, relação pressupõe seu plural, pelo fato de, em um ambiente fractal, todos os pontos estarem interligados, sem nenhum tipo de centralidade ou periferia; a segunda se articula à construção das relações, pois como estamos analisando conceitos com infinitos componentes, e estes, por sua vez, ultrapassam um ambiente que chamaremos de pensamento, é justo pressupor que as relações precisam ser construídas dentro de uma arquitetura subjetiva.

Partindo dessas premissas, podemos afirmar que vivemos em um momento histórico em que muitos olhares se voltam à perspectiva de se valorizar as diversidades culturais. A superação de hierarquias culturais em um processo de inteligibilidade recíproca é um dos desafios de quem se arrisca a adentrar nos estudos que analisam as diferentes culturas. A interculturalidade, nesse sentido, visa "mediar as diferenças, que caracterizam a singularidade e a essência de cada ser humano, abre a 
porta para uma nova perspectiva epistemológica que aponta para a compreensão da multiplicidade e da ambivalência, que constituem as identidades e as relações sociais" (CANDAU, 2002, p.178).

Este conceito de interculturalidade se projeta no espaço escolar e o movimento de observação e valorização da diversidade cultural entra na escola de diferentes formas, a saber: pelo currículo, e pelos discursos emancipatórios, assistencialistas, entre outros. O que nos interessa, neste momento, é reforçar a porosidade da escola com relação a estes movimentos. Sobre os estudos interculturais, vale ainda mencionar Fleuri (2003, p.31) quando afirma que "trata-se de abrir o olhar ao estranhamento, ao deslocamento do conhecido para o desconhecido, que não é só o outro sujeito com quem interagimos socialmente, mas também o outro que habita em nós mesmos". Ou seja, é nas várias dimensões e implicações que envolvem a diferença que se apoia um dos pilares dos estudos interculturais em educação. Dimensões, por se tratar de um espaço composto por diferentes culturas, e implicações, por estarmos situados em uma discussão específica em que a diferença se apresenta na diversidade cultural.

Parece conveniente afirmarmos que sistemas de referência a priori, construído em um espaço externo às relações culturais, provocam uma colonização dos saberes pertencentes às diferentes culturas. Se as ferramentas epistemológicas forem forjadas na racionalidade ou nas divindades, as relações culturais ficarão contaminadas por uma linguagem que esconde a diferença dos saberes que pertencem às culturas, que têm, por sua vez, outras formas de se relacionar com o mundo. Deste ponto de vista, analisar a forma com que observamos as diferentes culturas se projeta em uma relação de igualdade na relação. Para que, com isso, possamos "ler o mundo, nossa própria história e os distintos alfabetos que nos oferecem a diversidade das culturas". (BETANCOURT, 2004, p. 11, nossa tradução).

A recognição envolve princípios similares aos do sistema epistemológico a priori. Atua de forma mais silenciosa na subjetividade dos sujeitos herdeiros do iluminismo. Age em nível subjetivo, e atinge todas as camadas do corpo e seus afetos. Em um contexto intercultural, a recognição coloniza as diferentes culturas não hegemônicas de forma sofisticada. Sofisticada, pois a relação de causalidade no processo de colonização cultural se efetiva nas forças que atuam no sujeito, em suas ações e pensamentos, e se difunde nos artefatos culturais observados. Já o sistema a priori pertence a um sistema epistemológico legitimado metodologicamente. Os instrumentos são explícitos e muitas vezes pertencem às ciências exatas, mais especificamente à estatística.

A veracidade dessas afirmações não é óbvia. A recognição, como analisa Deleuze (2000), encontra uma relação objetiva que a reforça. A matematização do mundo, os discursos científicos, as filosofias hegemônicas e a arte racional se articulam ao se encontrarem com o cogito cartesiano. $O$ sujeito cartesiano, a cada novo contato com estes artefatos racionais, reforça e constrói um espectro de racionalidade que infla a cada nova passagem. Nesse sentido, basta encontrarmos uma cultura que não tenha seus pilares construídos na relação sujeito-verdade-transcendência para o estranhamento acontecer. Esse estranhamento pode levar à construção de novos saberes ou minimizar a diferença em um processo de acomodação transcendente.

Diante dessas ideias, podemos traçar algumas alternativas à não colonização cultural, princípio que envolve os estudos interculturais em educação. Na lógica dos sentidos, Deleuze (2000) aponta que 
o conceito de diferença nasce em uma espécie de abertura que legitima todos os sentidos como mecanismos afetados pelo mundo. São nossas faculdades de percepção que se conectam com o real em toda a sua amplitude - a relação racional real se amplia e cinde o sujeito. Todas as faculdades estão abertas no mundo dos sentidos e a diferença se revela, neste ponto de vista, na direção sujeitoobjeto. Se pensarmos de forma inversa, em um sistema que projeta a dinâmica dos sentidos em nível de linguagem, estamos em uma camada sub-representativa. Há uma conexão entre o sujeito que expressa a diferença em pensamento e as ausências, conforme Santos (2002), construídas como tal. Trata-se de alargar a conexão entre as diferentes culturas em um processo que provoque a construção de uma subjetividade intercultural.

Sem dúvida precisamos dar mais um passo importante na relação entre o conceito de diferença e os estudos interculturais em educação. Se os estudos interculturais em educação têm como principal objetivo desierarquizar as culturas e construir novos conceitos a partir das relações interculturais, e o conceito de diferença, em suas diferentes dimensões, nos auxilia a dar consciência de nossa subjetividade que muitas vezes privilegia a recognição, podemos inferir que esta relação implica um processo de construção.

Acreditamos que a construção de um sujeito intercultural não se limita à percepção da diversidade cultural. As modificações são mais profundas e se articulam à construção conceitual. Segundo Deleuze (2010), a filosofia é a arte de fabricar conceitos. Nesse sentido, existe um estreitamento entre a filosofia e a construção das relações interculturais. As relações precisam ser construídas em nível conceitual. Matemáticas interculturais, gastronomias interculturais, artes interculturais, ciências interculturais. Estas aproximações são construídas nos encontros e desencontros entre os diferentes saberes, o que exige lateralidade entre as diferentes culturas. Esta, por sua vez, é garantida pelo sujeito que constrói estas relações, o sujeito intercultural, que em cada nova volta de aproximação e construção conceitual, no ambiente de diversidade cultural, constrói a si mesmo.

Aproximar a filosofia da diferença e os estudos interculturais em educação nos permite lembrar a potência que temos de construir novas relações que podem ser transportadas e analisadas no ambiente escolar, fértil para a construção conceitual que perpassa as diferentes disciplinas e suas organizações epistêmicas. O sujeito intercultural pode se construir nas relações disciplinares que carregam em seus territórios epistemológicos aspectos culturais que valem a exploração geográfica.

Nessa perspectiva, os estudos interculturais em educação constroem um espaço de criação epistemológica que legitima os saberes emergentes que a filosofia da diferença permite revelar. Temos uma espécie de retorno à potência de conhecer na construção de uma subjetividade intercultural. Deste ponto de vista, há um deslocamento da ideia de verdade: "a ideia de verdade é a ideia enquanto ela se explica pela nossa potência de conhecer" (DELEUZE, 2017, p. 152), que se locomove sobre linhas finas que a construção das relações interculturais provocam em nível de pensamento.

Enfatizamos, desta forma, que os estudos interculturais em educação permitem estabelecer um conjunto de possibilidades de construção de conceitos e subjetividades. Revelar os conhecimentos das diferentes culturas e construir relações entre elas é uma possibilidade de construção de sujeitos interculturais. Como as relações precisam ser construídas, a filosofia da diferença e o próprio conceito 
de diferença, e todas suas implicações surgem como mecanismos de expressão - alavancas que permitem observar as ausências analisadas por Santos (2002).

A expressão, nesse contexto, parece nos permitir manifestar pensamentos por meio de palavras, nos colocando como sujeitos participantes. Participar, nesse sentido, não é imitar; não é imitar as leis matemáticas de uma cultura eurocêntrica que se define em um ambiente metafísico, imitar as regras da linguística que reafirmam a recognição na análise de diferentes línguas. Participar não é imitar - é construir. Desta forma, os estudos interculturais em educação constroem um movimento em que a participação é efetiva. Não se limita à imitação, mas permite a construção de conceitos tomando como linguagem as diferentes culturas. Deste ponto de vista, a ciência se alimenta da participação ativa de sujeitos que se aventuram nas fronteiras conceituais dos saberes que as diferentes culturas irradiam.

\section{CONSIDERAÇÕES}

Duas forças concorrentes empregadas sobre um objeto geram uma terceira força que está na mesma direção e sentido do deslocamento do objeto. Chamamos esta força de vetor resultante, como podemos observar na imagem abaixo.

Imagem I: Soma de vetores

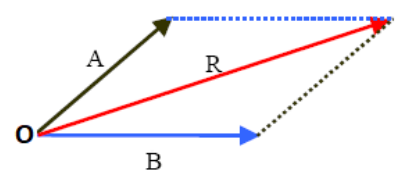

Fonte: os pesquisadores.

$\mathrm{Na}$ imagem I, podemos observar algumas letras: O, A, B e R. A letra O representa um objeto qualquer, como uma cadeira. $A$ letra $A$, um vetor-força que está agindo sobre o objeto. $A$ letra $B$, da mesma forma, é um vetor-força que age sobre o objeto $O$. Ambos os vetores com suas respectivas intensidades, sentido e direção. A letra $R$ é o vetor resultante, ou seja, aquele que indica a força, sentido e direção pela qual passará o objeto $O$. Este tipo de análise é efetuada em um ramo da física chamado de dinâmica dos corpos, com vasta aplicação nas mais diferentes culturas por se tratar de uma ferramenta muito potente na medição do comportamento dinâmico de objetos que se propagam no espaço ou na terra. Não vamos adentrar nas consequências práticas e abstratas que estas relações provocam na física e na ciência de modo geral. Queremos apenas frisar dois pontos. O primeiro está relacionado ao conjunto de vetores envolvidos em uma dinâmica de corpos. Isso significa que, no deslocamento de qualquer objeto, pode agir um grande conjunto de vetores. Na imagem I, destacamos apenas os vetores $A$ e $B$, porém poderíamos ter outros com o mesmo ponto de atuação. $O$ que vale destacar é que o vetor resultante, mesmo com uma quantidade extremamente maior de vetores envolvidos, sempre aparece objetivamente no deslocamento do objeto. O segundo ponto é no que se refere à junção e à análise do vetor resultante. Por trás do vetor resultante $\mathrm{R}$ existe um somatório. $\mathrm{Ou}$ seja, a soma do vetor A mais o vetor $B$ resulta no vetor $R$, que na prática é o deslocamento do objeto, 
seu sentido e direção. Esta soma também pode ser observada em uma dinâmica com um conjunto muito maior de vetores força. Deste ponto de vista, podemos concluir que em todo deslocamento de objeto que envolve qualquer dinâmica de forças existe uma soma que gera um vetor resultante - outra força que é derivada das forças que agiam no objeto empiricamente.

Não estamos interessados na linguagem ou nos axiomas internos que permitem fazer esta análise matematicamente usando a álgebra linear. Também não queremos construir uma imagem universal das dinâmicas de força que, como sabemos, é válida em apenas alguns contextos que se situam fora da geometria Não-Euclidiana e da Teoria da Relatividade. O que queremos destacar é o aspecto da diferença que envolve o surgimento do vetor resultante. O vetor resultante não existe $a$ priori, pois depende dos fluxos de forças que envolvem o deslocamento. Ele não pode ser captado por um processo de recognição, pois não está contido no objeto analisado - cada vetor resultante é único nos fenômenos de deslocamento observados. Desta forma, e como consequência, nas dinâmicas de deslocamento efetuadas no real, o vetor resultante só pode ser analisado se escolhermos o conjunto de vetores que serão considerados como agentes de deslocamento, o vetor A e B na imagem I. Assim, em ambientes de caos de forças, o vetor resultante precisa ser construído no processo de escolarização.

Seguindo na esteira da física, o vetor resultante é um exemplo do conceito de diferença aplicado à dinâmica de forças. O vetor resultante é ao mesmo tempo virtual, ao processo aparente, e real no ato da interferência do observador. Foi com esta pretensão que construímos o presente artigo. Relacionar o conceito de diferença e os estudos interculturais em educação envolve um processo de construção, como o vetor resultante; não se apresenta de forma objetiva, o que exige a interferência do observador na escolha dos vetores que agem sobre o fenômeno.

O que construímos foi um vetor resultante, analisado a partir da soma dos vetores: o conceito de diferença e os estudos interculturais em educação, cada vetor com sua particularidade, no que estão implicados o conceito de diferença e os desafios de aproximar um espaço de não representação através de um conceito, que transbordam o espaço escolar na luta pela não homogeneização dos saberes construídos culturalmente. E o vetor resultante, resultado da soma desses vetores, em última análise, catalisa a construção de sujeitos interculturais que se formam na construção conceitual e no contato com o diferente.

Se existem forças que agem em nós que nos deslocam em sentido amplo, que atuam nas diferentes culturas que as deslocam em sentido amplo, as forças que agem em nós, somadas com as forças que agem na cultura com a qual desenvolvemos uma relação de pertencimento, geram que vetor resultante? O vetor resultante se objetiva nas nossas ações e pensamento, prioridades e emoções. Em qual tipo de vetor resultante nos transformamos ao nos alinharmos à cultura da qual nos consideramos parte? Essas perspectivas abrem possibilidade de desenvolver criticidade subjetiva a partir do resultado que percebemos em nós mesmos. 


\section{REFERÊNCIAS}

1. ARENDT, H. A vida do espírito. Rio de Janeiro: Civilização Brasileira, 2008.

2. BAUMAN, Z. Legisladores e Interpretes. Rio de Janeiro: Zahar, 2010.

3. BETANCOURT, R. F. La Interculturalidad a prueba. 2004.

4. CANDAU, V. M. Sociedade, Educação e Culturas(s). Rio de Janeiro: Vozes, 2002.

5. DELEUZE, Gilles. Diferença e repetição. Lisboa: Relógio d Água, 2000. 493 p.

6. DELEUZE, Gilles. Espinosa e o problema de expressão. São Paulo: Editora 34. 2017. 247 p.

7. DELEUZE, G. e GUATTARI, F. O que é a filosofia? São Paula. Editora 34. 2010.

8. FLEURI, R.M. Interculturalidade e Educação: para além da diversidade. Vol. 23, p.16-25. Rio de Janeiro. 2003.

9. SANTOS, B. S. Para uma sociedade da ausência e uma sociedade das emergências. Revista crítica das ciências sociais. 2002. p. 237-280.

\section{Juliano Bona}

Possui Graduação em Matemática pela Fundação Universidade Regional de Blumenau - Furb (2005). Atua na área de ensino fundamental como professor de matemática na Rede Pública Municipal de Timbó. Mestre em Educação pela Fundação Universidade Regional de Blumenau - Furb (2010). Tem experiência no Ensino Superior nas seguintes áreas: Educação Matemática, Cálculo Diferencial e Integral, Geometria e Álgebra Linear. Atualmente é aluno do Doutorado em Educação - Univali Universidade do Vale do Itajaí.

\section{Camila Thaisa Alves Bona}

Possui graduação em Letras pela Universidade Regional de Blumenau e Mestrado em Educação pela mesma instituição. Foi professora de Língua Portuguesa e Inglesa nas redes pública e particular, atuando no ensino fundamental e educação infantil. Atualmente trabalha como professora de Língua Portuguesa na rede pública de ensino do município de Timbó, Santa Catarina. 


\section{José Marcelo Freitas de Luna}

Possui graduação em Letras pela Universidade Federal da Paraíba; mestrado em Letras (Inglês e Literatura Correspondente) pela Universidade Federal de Santa Catarina, com estágio sanduíche na Universidade de Birmingham (Inglaterra); especialização em Administração Universitária pela Organização Universitária Interamericana e Universidade Católica de Goiás, com estágio na Universidade de Ottawa (Canadá); especialização em Gestão da Cooperação Técnica Internacional, pela FEA/USP; doutorado em Linguística pela Universidade de São Paulo, com estágio sanduíche na Universidade de Cambridge (Inglaterra); e pós-doutorado, na Universidade do Texas em Austin (Estados Unidos). Atualmente, é professor e pesquisador do Programa de Pós-Graduação (Mestrado e Doutorado) em Educação da Universidade do Vale do Itajaí, professor visitante da Faculdade de Letras da Universidade de Coimbra e Investigador do Centro de Estudos das Migrações e das Relações Interculturais da Universidade Aberta de Portugal.

\section{Como citar este docuento:}

BONA, Juliano; BONA, Camila Thaisa Alves; LUNA, José Marcelo Freitas de. Subjetividade e diferença: implicações para os estudos interculturais em educação. Reflexão e Ação, Santa Cruz do Sul, v. 27, n. 3, p. 220-231, oct. 2019. ISSN 1982-9949. Disponível em: <https://online.unisc.br/seer/index.php/reflex/article/view/11630>. Acesso em: doi:https://doi.org/10.17058/rea.v27i3.11630. 